\title{
CHRONIC INFLAMMATORY DEMYELINATING POLYNEUROPATHY IN AN ADOLESCENT WITH TYPE 1 DIABETES MELLITUS
}

\author{
Crésio Alves, Zilda Braid, Nadja Públio
}

Chronic inflammatory demyelinating polyradiculopathy (CIDP) is an immune-mediated disorder for which specific clinical cerebrospinal fluid (CSF), electrophysiologic and histological criteria have been proposed'. CIPD is an uncommon cause of childhood polyneuropathy. Descriptions of children with CIPD are scarce. Therefore, this article intends to report a case about an adolescent with type 1 diabetes mellitus (TIDM) with a satisfactory therapeutic response to immunoglobulin and methylprednisolone.

This presentation highlights the importance of investigating diabetic patients, including children, with polyneuropathy in an attempt to identify the ones with demyelinating polyneuropathy, because of the likelihood of these patients to benefit from immumodulatory and/or immunossupressive treatment.

\section{CASE}

Male, 14 year-old, with a seven year history of TIDM and one year history of diabetic nephropathy. Under insulinotherapy and captopril with unsatisfactory glycemic control. Nine months before the initial evaluation he presented pain, paresthesia and a progressive, symmetric muscular weakness, in both lower limbs. After five months of therapeutic failure under carbamazepine and amytryptiline, he was referred to our service. The initial evaluation showed a mild and symmetric, proximal and distal lower limb weakness (the upper limbs were not affected). The proximal compromise was worse than distal. There were patellar and Achilles tendon hyporeflexia, with absence of Babinski sign. Pain, vibratory and position stimulus modalities were normal, although tactile sensory tests evidenced paresthesias. Anal and vesical sphincter function and muscular tone were preserved.

Complete blood count, erythrocyte sedimentation rate, urea, creatinine, electrolytes, AST, ALT, GGT, alkaline phosphatase, prothrombine time, total proteins, albumin, creatinekynase (CK), CK-MB, thyroid function tests, lipid profile and cerebrospinal fluid evaluation were normal.

The first electromyography (EMG), done five months after the beginning of the neurologic symptoms (Nihon Khoden Elec- tromyography, 4 channels), evidenced decreased conduction velocities with normal amplitude in the median, ulnar, left fibular and posterior tibial nerves, except in the deep right fibular nerve, where although the amplitude was $75 \%$ of the lower limit of the normal range (LLNR), the conduction study was $80 \%$ lower than LLNR. The distal motor latencies of the median, left ulnar, superficial fibular and sural nerves were prolonged (above 120\% of the normal range). The $\mathrm{F}$ waves presented prolonged latencies in the ulnar and posterior tibial nerves. The examination with monopolar needle showed decrease in the recruitment of action potentials of the motor unit.

The patient was initially treated with human immunoglobulin (400 mg/ Kg/day, IV, 5 days), improving the sensory symptoms for about a month, with subsequent relapse, in smaller intensity. There was not improvement of the lower limb weakness. A second EMG, performed 2 months after therapy with immunoglobulin, evidenced increment in the amplitude of the sensory and motor action potential, and decrease of the distal motor latencies, with persistence of the conduction velocities though. The examination showed $\mathrm{F}$ waves with prolonged latency in the left ulnar and posterior tibial nerves, with normal latency in the left ulnar nerve. The examination with monopolar needle showed normal recruitment.

Due to partial response to immunoglobulin, it was decide on instituting treatment with methylprednisolone $(900 \mathrm{mg} /$ day, IV, 5 days), without any side effect. At reassessment, three months after starting corticotherapy, the patient presented improvement of neurologic symptoms. A third EMG conducted 2 months after methylprednisolone displayed normal amplitude, with slight decrease in the sensory (median, ulnar, right sural and left superficial nerves) and motor (median and left fibular nerves) conduction velocity, and prolonged distal latency in the median nerves. The $\mathrm{F}$ waves presented normal latencies. Examination with monopolar needle showed normal recruitment.

Tables 1 and 2 summarizes the main EMG findings before and after the treatment with immunoglobulin and methylprednisolone.

\section{POLINEUROPATIA INFLAMATÓRIA DESMIELINIZANTE CRÔNICA EM UM ADOLESCENTE COM DIABETES MELITO TIPO 1}

Pediatric Endocrinology Service, Hospital Universitário Professor Edgard Santos, Faculty of Medicine, Universidade Federal da Bahia, Salvador BA, Brazil. Received 5 September 2008, received in final form 5 December 2008. Accepted 19 February 2009.

Dr. Crésio Alves - Rua Plínio Moscoso 222 / 601 - 40157-190 Salvador BA - Brasil. E-mail: cresio.alves@uol.com.br 
Table 1. Eletroneuromyographic findings (motor potentials) before and after treatment with immunoglobulin and methylprednisolone.

\begin{tabular}{|c|c|c|c|c|c|c|}
\hline \multirow[t]{2}{*}{ Nerve } & \multicolumn{2}{|c|}{ Amplitude (N: $\geq 4 \mathrm{mV}$ ) } & \multicolumn{2}{|c|}{$\begin{array}{l}\text { Latency } \\
\text { upper limbs (N: } \leq 3.9 \mathrm{~m} / \mathrm{seg}) \\
\text { lower limbs (N: } \leq 4.9 \mathrm{~m} / \mathrm{seg})\end{array}$} & \multicolumn{2}{|c|}{$\begin{array}{c}\text { Conduction velocity } \\
\text { upper limbs ( } \mathrm{N}: \geq 50 \mathrm{~m} / \mathrm{seg}) \\
\text { lower limbs ( } \mathrm{N}: \geq 40 \mathrm{~m} / \mathrm{seg} \text { ) }\end{array}$} \\
\hline & $\mathrm{R}$ & L & $\mathrm{R}$ & $\mathrm{L}$ & $\mathrm{R}$ & L \\
\hline \multicolumn{7}{|l|}{ Median } \\
\hline At diagnosis & - & 7 & - & 4.2 & - & 40.65 \\
\hline After immunoglobulin & 9.3 & 6.6 & 4.3 & 3.9 & 40.65 & 38.89 \\
\hline After methylprednisolone & 9 & 7.27 & 3.6 & 3.6 & 47.17 & 44.55 \\
\hline \multicolumn{7}{|l|}{ Ulnar } \\
\hline At diagnosis & - & 8.2 & - & 3.25 & - & 42.86 \\
\hline After immunoglobulin & 10 & 12.2 & 3 & 3 & 41.23 & 44.23 \\
\hline After methylprednisolone & 8.8 & 7.6 & 2.2 & 2.6 & 49.58 & 50 \\
\hline \multicolumn{7}{|l|}{ Fibular } \\
\hline At diagnosis & 3.0 & 4.3 & 6.05 & 8.3 & 31.79 & 36.67 \\
\hline & (75\% LLNR) & & & (169\% ULNR) & (79\% LLNR) & \\
\hline After immunoglobulin & 4.3 & 6.3 & 6 & $\begin{array}{c}6.8 \\
(138 \% \text { ULNR) }\end{array}$ & 32.29 & 30.91 \\
\hline After methylprednisolone & 4.3 & 4.67 & 4.5 & 4.9 & 40.12 & 39.16 \\
\hline \multicolumn{7}{|l|}{ Tibial } \\
\hline At diagnosis & 7.7 & 7.9 & $\begin{array}{c}6.7 \\
(136 \% \text { ULNR) }\end{array}$ & $\begin{array}{c}7.15 \\
\text { (145\% ULNR) }\end{array}$ & - & - \\
\hline After immunoglobulin & 11.7 & 13.5 & 4.8 & 5.9 & - & - \\
\hline After methylprednisolone & 11.2 & 8.6 & 3.6 & 3.6 & - & - \\
\hline
\end{tabular}

$\mathrm{N}$ : normal reference values; ULNR: upper limit of the normal range; LLNR: lower limit of the normal range; R: right; L: left.

Table 2. Eletroneuromyographic findings (sensitive potentials) before and after treatment with immunoglobulin and methylprednisolone.

\begin{tabular}{|c|c|c|c|c|c|c|}
\hline \multirow[b]{2}{*}{ Nerve } & \multicolumn{2}{|c|}{ Amplitude (N: $\geq 5 \mu \mathrm{V})$} & \multicolumn{2}{|c|}{$\begin{array}{c}\text { Latency } \\
\text { upper limbs (N: } \leq 3.9 \mathrm{~m} / \mathrm{seg}) \\
\text { lower } \operatorname{limbs}(\mathrm{N}: \leq 4.9 \mathrm{~m} / \mathrm{seg})\end{array}$} & \multicolumn{2}{|c|}{$\begin{array}{l}\text { Conduction velocity } \\
\text { upper limbs ( } \mathrm{N}: \geq 50 \mathrm{~m} / \mathrm{seg}) \\
\text { lower limbs ( } \mathrm{N}: \geq 40 \mathrm{~m} / \mathrm{seg} \text { ) }\end{array}$} \\
\hline & $\mathrm{R}$ & L & $\mathrm{R}$ & L & $\mathrm{R}$ & L \\
\hline \multicolumn{7}{|l|}{ Median } \\
\hline At diagnosis & - & 21 & - & 3.08 & - & 43.83 \\
\hline After immunoglobulin & 36.7 & 43 & 3.64 & 3.76 & 34.34 & 34.57 \\
\hline After methylprednisolone & 30 & 70 & 3.2 & 3 & 41.25 & 42.67 \\
\hline \multicolumn{7}{|l|}{ Ulnar } \\
\hline At diagnosis & - & 22 & - & 2.6 & - & 44.23 \\
\hline After immunoglobulin & 26.7 & 40 & 3.08 & 3.08 & 35.71 & 37.34 \\
\hline After methylprednisolone & 30 & 30 & 2.24 & 3.36 & 49.11 & 32.74 \\
\hline \multicolumn{7}{|l|}{ Sural } \\
\hline At diagnosis & 12.7 & 23.3 & 2.56 & 2.5 & 35.16 & 34 \\
\hline After immunoglobulin & 40 & 43.3 & 3.24 & 3 & 32.41 & 33.3 \\
\hline After methylprednisolone & 20 & 30 & 2.2 & 2.16 & 39.09 & 46.3 \\
\hline
\end{tabular}

$\mathrm{N}$ : normal reference values; $\mathrm{R}$ : right; $\mathrm{L}$ : left.

\section{DISCUSSION}

Chronic inflammatory demyelinating polyradiculopathy is an acquired neuropathy characterized by a chronic, rapidly progressive, proximal and distal symmetric weakness, associated with hyporeflexia and sensory symptoms'. It has an immunologic pathophysiology involving both the humoral and the cellular immunologic response, which supports the rationale to the immunotherapy ${ }^{1,2}$.

Diabetes mellitus is the most common cause of peripheral neuropathy in industrialized countries and CIPD must be considered in the differential diagnosis of the diabetic somatic neuropathies ${ }^{3}$. However, the distinction of 
diabetic somatic polyneuropathy from CIDP is not a simple task. While CIDP progresses in months, with relapses in a third of the cases, in the diabetic neuropathy the course is slower, progressing in years, and usually related to the length of diabetes ${ }^{1-4,5}$. In addition, the electromyography and nerve conduction studies reveal demyelination with nervous conduction abnormalities, contrary to the axonal pattern of diabetic neuropathy.

The diagnosis of the classic diabetic CIDP ${ }^{6}$, is achieved when the patient presents: (1) diabetes; (2) progressive chronic or relapsing, sensory or sensory-motor polyneuropathy, with length of at least 2 months, associated with hyporeflexia; (3) eletrophysiologic criteria for demyelinating neuropathy; (4) increase of CSF proteins without increase of leukocytes; (5) clinical improvement with immunotherapy; and (6) in selected cases, evidence of loss of myelinated fibers in the nerve biopsy. However, besides the classical presentation, CIDP encompasses a large set of phenotypes, including one with a normal CSF study. Therefore there is not a single diagnostic pattern which can cover every expression of the disease ${ }^{1,2,4,7}$.

In this patient, the diagnosis of CIDP was based on: diagnosis of TIDM, progressive pattern of the neuropathy, and electromyography studies compatible with demyelinating polyneuropathy, without evidence of axonal lesion.

The axonal degeneration and the chronic evolution are predictors of a worse prognosis ${ }^{2}$. Simmons et al. ${ }^{8}$ and Hattori et al. ${ }^{9}$ reported subacute evolution and a predominantly motor neuropathy in the juvenile age group, with a better recovery after relapse than adults. On the other hand, Nevo et al..$^{10}$ did not find significant differences in the clinical characteristics of children and adults with CIDP.

The therapeutic scheme of choice is elusive. Some authors start with human immunoglobulin, while others prefer costicosteroids ${ }^{2,7,11}$. The immunosuppressive drugs are reserved for failure of the initial therapy. The comparison among studies about therapeutic response is hindered by the diversity of presentations of CIDP, the type and the dose of the drugs employed'.

The mechanism of action of immunoglobulin remains uncertain. Two double-blind randomized clinical trial demonstrated benefits of the use of immunoglobulin ${ }^{12}$. Side effects include renal dysfunction, thromboembolic events and high cost ${ }^{4}$.

The exact mechanism of action of steroids in CIDP is unknown. In mild disease, one can start prednisone (1 $\mathrm{mg} / \mathrm{Kg} /$ day) and when improvement of symptoms follows, restart a gradual decrease. If relapse or worsening of symptoms occurs, the dose can be increased or an im- munosuppressive drug can be added up. When the option is methylprednisolone, the start dose, in adults, was $1.000 \mathrm{mg} /$ day for 3 to 5 consecutive days, afterwards tapering off the dose $\mathrm{e}^{11}$. Among the side effects were: poor glycemic control. weight gain, hypertension and Cushing syndrome features.

This article advises about the importance of thinking of CIDP when evaluating a sensory-motor diabetic peripheral neuropathy.

\section{REFERENCES}

1. Kalita J, Mistra UK, Yadav RK. A comparative study of inflammatory demyelinating polyradiculoneuropathy with and without diabetes mellitus. Eur J Neurol 2007;14:638-643.

2. Said G. Chronic inflammatory demyelinating polyneuropathy. Neuromuscul Disord 2006;16:293-303.

3. Said G. Focal and multifocal diabetic neuropathies. Arq Neuropsiquiatr 2007;65:1272-1278.

4. Sharma KR, Cross J, Farronay O, Ayyar DR, Shebert RT, Bradley WG. Demyelinating neuropathy in diabetes mellitus. Arch Neurol 2002b;59:758-765.

5. Stewart JD, McKelvey R, Duncan L, Carpenter S, Karpati G. Chronic inflammatory demyelinating polyneuropathy (CIPD) in diabetics. J Neuro Sci 1996;142:59-64.

6. Cornblath DR, Asbury AK, Albers JW, et al. Report from an Ad Hoc Sucommittee of the American Academy of Neurology AIDS Task Force: research criteria for the diagnosis of chronic inflammatory demyelinating polineuropathy (CIPD). Neurology 1991;41:617-618.

7. Saperstein D, Katz J, Amato A, Barohn R. Clinical spectrum of chronic acquired demyelinating polyneuropathies. Muscle Nerve 2001;24:311-324.

8. Simmons Z, Wald JJ, Albers JW. Chronic inflammatory demyelinating polyradiculoneuropathy in children: II. Longterm follow-up, with comparison to adults. Muscle Nerve 1997;20:1569-1575.

9. Hattori N, Misu K, Koike H, et al. Age of onset influences clinical features of chronic inflammatory demyelinating polyneuropathy. J Neurol Sci 2001;184:57-63.

10. Nevo Y, Pestronk A, Kornberg AJ, et al. Childhood chronic inflammatory demyelinating neuropathies: clinical course and long-term follow-up. Neurology 1996:47:98-102.

11. Lopate G, Pestronk A, Al-Lozi M. Treatment of chronic inflammatory demyelinating polyneuropathy with high-dose intermittent intravenous methylprednisolone. Arch Neurol 2005;62:249-254.

12. Mendell JR, Barohn RJ, Freimer ML, et al., and The Working Group on Peripheral Neuropathy. Randomized controlled trial of IVIg in untreated chronic inflammatory demyelinating polyradiculoneuropathy. Neurology 2001;56:445-449. 